\title{
Increasing Port Performance through Port Navigation Safety Assessment using the Formal Safety Assessment Method (Case Study Port of Tanjung Priok - Indonesia)
}

\author{
Sahlan Ridwan and Sunaryo ${ }^{*}$ \\ Naval Architecture and Marine Engineering Study Program, Universitas Indonesia, Jl. Kampus UI \\ Depok 16424, Indonesia
}

\begin{abstract}
The study is aimed to assess the navigation safety in the port surrounding the area as part of the Indonesian Government's efforts to increase the port performance and minimize the cost of maritime logistics. The port navigation system and infrastructure such as vessels traffic management system, navigation lanes, port basin, quay, etc. play an important role in determining the productivity and efficiency of the port, especially in the busy port such as Tanjung Priok, Indonesia. Any accident would interrupt port activities and creates unnecessary costs. Formal Safety Assessment method, as introduced by the International Maritime Organization was implemented in the study. The assessment was carried out using qualitative and quantitative risks analyses, based on the available data and information gathered from various sources. It was identified that accidents occurred in the port waterfront were mainly due to the ships, environment, human factors, and management. Results of the assessment were then used as the basis for proposing an improvement strategy.
\end{abstract}

Key words: Accident, efficiency, risk analysis, traffic management.

\section{Introduction}

As an archipelagic country, Indonesia is very much depended on the sea transportation system as part of the logistic chain and connectivity between its more than 17000 islands. As part of sea transportation system port plays an important role in determining the costs of logistics. Port contributes to the development of trade, economy, and industry in its surrounding region, therefore in order to minimize the costs of logistics, one of the approaches is through increasing the performance of the port. Port performance is very much determined by the smoothness of its operation, such as loading and unloading of cargo, movement, and arrangement of containers, vessels controlling traffic system, etc. The high activities in the port would also create a certain level of accident risks. One among other things is ship accidents in the port navigation area, such as port entrance and port basin, which could disturb port operation and cause unnecessary loss.

*Corresponding author: naryo@eng.ui.ac.id 
Port of Tanjung Priok is the largest and busiest port in Indonesia. Based on the report published by Indonesia Port Corporation II in 2016, there were $20598000 \mathrm{t}$ of cargoes being shipped through, and 14393 of ships called at the port of Tanjung Priok [1].

Based on these considerations, a study has been carried out to assess the navigation safety in the port of Tanjung Priok area to propose a strategy for minimizing potential accidents through the identification of their root causes.

In order to obtain an adequate level of safety, a system of safety has to exist at the international level which will be capable of bringing adequate necessary measures and which will monitor the implementation of these measures using various instruments and through various institutions. For this purpose, International Maritime Organization (IMO) has published a systematic and integrated safety guideline using Formal Safety Assessment (FSA) [2]. FSA is a rational and systematic process for assessing the risks relating to maritime safety and the protection of the marine environment and for evaluating the costs and benefits of IMO's options for reducing these risks.

\section{Methodology}

Before applying the five steps of FSA, accident data were gathered from available sources, to identify the type and number of accidents for a certain period around the port of Tanjung Priok. The data are shown in Figure 1 for the number of accidents based on the type of ships from 2013 to 2017, and Figure 2 for the number of accidents based on the type of accident then used as the bases for conducting the Formal Safety Assessment (FSA).

It is identified from Figure 1 that the highest type of ships involved in accidents are categorized as other ships, which means that the ships were not intended to berth at the port terminals but to neighboring terminals or for other purposes. Based on further investigation, the types and number of ships in this category that involved in the accidents were: 11 barges, 10 tug boats, two supply vessels, and one research vessel [3]. From the data presented in Figure 2 provides information that grounding and collision were the highest types of accidents occurred in the specified period.

FSA comprises five steps i.e., hazards identification, risk analysis, risk control options, cost-benefit assessment, and recommendations for decision making [2].

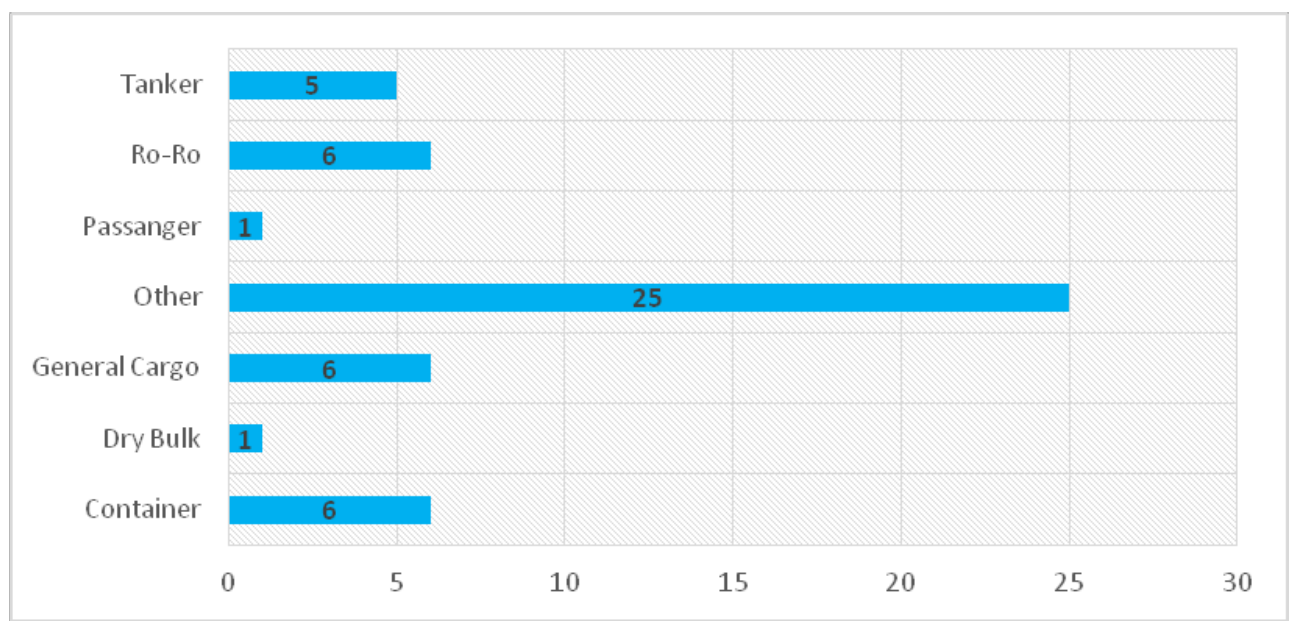

Fig. 1. Accidents data based on the type of ships involved 


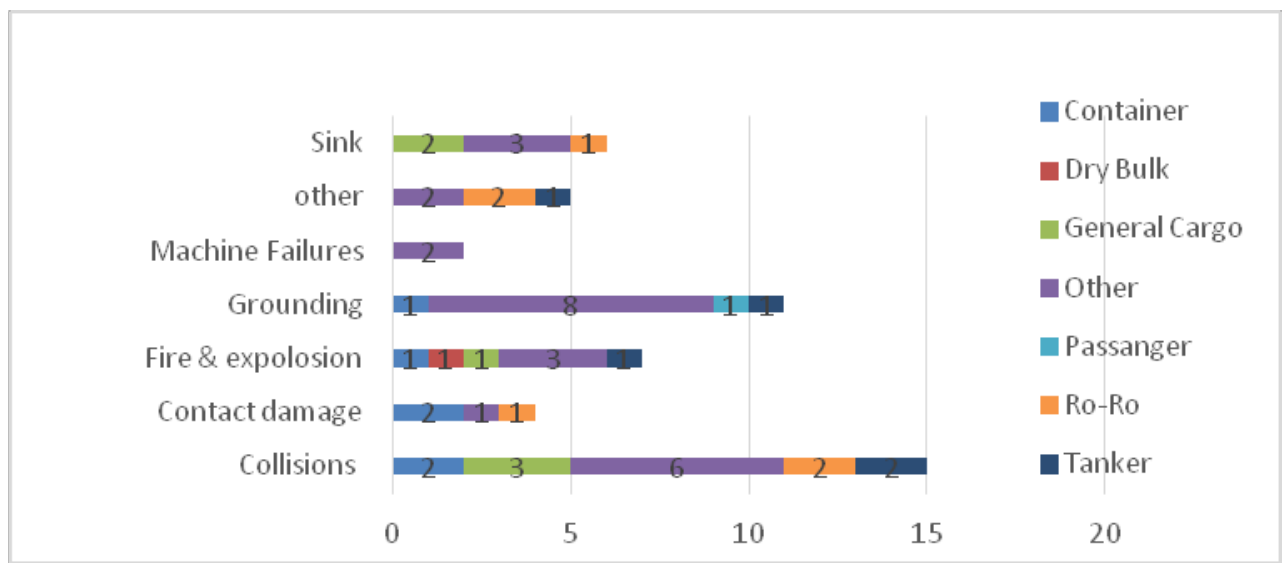

Fig. 2. Accidents data based on the type of accidents

\subsection{Hazard identification}

The main objective of this step is to identify hazards that might cause safety problems or accidents. Kuo [4] defines a hazard as something which can lead to an undesired outcome in the process of meeting an objective. This can involve injury to human beings, damage to property, or harm to the environment, or a combination or some or all of these three. In this step, the qualitative data were converted into quantitative data, and the outputs were a list of hazards and their related scenarios. In order to set a priority of the study, the investigation is only focussed on two highest hazards based on the accidents data had been recorded, i.e. collision and grounding. The potential causes of these hazards were then also identified, where potential causes of a collision are: navigation problems, human error, mooring or anchoring failures; and potential causes of grounding are: effect of weather, effect of environment, navigation failures, and ship equipment failures.

\subsection{Risk analysis}

According to Ayyub et al. [5], risk is defined as potential losses and rewards resulting from exposure to a hazard or as a result of the risk event. Risk analysis involves event probability and event consequence, as shown in Formula 1.

$$
\mathrm{R}=\mathrm{P} \times \mathrm{C}
$$

Where $\mathrm{R}$ is risk level; $\mathrm{P}$ is probability; and $\mathrm{C}$ is consequence.

Risk can be categorized into intolerable, tolerable, and acceptable [6], dependent on the object of the assessment and the acceptance of the related stakeholders. Risks are classified as intolerable regardless of the benefits associated with the activity because they have a high level of severe consequences, which might create a catastrophic condition, casualties, or major financial loss. An intolerable risk must be eliminated or reduced so that it falls into one of the other two categories, or there must be exceptional reasons for the activity or practice to continue. Tolerable risks are the risks that people are generally prepared to tolerate to secure their benefits. They might create inconveniences, minor injuries that need only first aid treatments, and minor financial loss but at a certain extent, can still be acceptable. Tolerable risks must be properly assessed and controlled to keep the residual risk at an acceptable level of safety and must be reviewed periodically to ensure they 
remain that way. Acceptable risks are those that people would regard as insignificant or trivial in their daily lives, or which exist, but have no practicable mitigation. They might create minor inconveniences but no injuries, or very low financial loss. Improvements are needed if their benefits outweigh the costs of doing them. Risk levels are shown in Table 1.

Probability is categorized as frequent, likely, occasionally, seldom, and unlikely [7] as shown in Table 2. Frequent when the accident occurs more than once per year, likely when an accident occurs less than once per year, occasionally when an accident occurs once in 3 $\mathrm{yr}$, seldom when an accident occurs once in $5 \mathrm{yr}$, and unlikely when an accident occurs once or less in $10 \mathrm{yr}$.

The consequence is categorized as major, moderate, and minor [8] as shown in Table 3. Major when the accident might cause death or fatal injury to human or total damage to the ship system and/or structure. Moderate when an accident might cause injury to human and/or damage to ship and/or structure. Minor when an accident might cause minor injury to human or minor damage to ship or structure.

Table 1. Risk level

\begin{tabular}{cc}
\hline Risk level & Risk category \\
\hline 16 to 25 & Intolerable \\
6 to 15 & Tolerable \\
Under 5 & Acceptable \\
\hline
\end{tabular}

Table 2. Accident occurance probability

\begin{tabular}{ccc}
\hline Description & Scale & Occurrence \\
\hline Frequent & 5 & More than once per year \\
Likely & 4 & Less than once in per year \\
Occasionally & 3 & Once in $3 \mathrm{yr}$ \\
Seldom & 2 & Once in $5 \mathrm{yr}$ \\
Unlikely & 1 & Once or less in $10 \mathrm{yr}$ \\
\hline
\end{tabular}

Table 3. Accident consequence/severity

\begin{tabular}{lcl}
\hline \multicolumn{1}{c}{ Description } & Level & \multicolumn{1}{c}{ Severity } \\
\hline Major & 5 & $\begin{array}{l}\text { Might cause death or fatal injury to human and total damage } \\
\text { to the ship system/structure }\end{array}$ \\
Moderate & 3 & $\begin{array}{l}\text { Injury to human and damage to ship system or structure } \\
\text { Minor }\end{array}$ \\
\hline
\end{tabular}

\subsection{Risk control options}

Based on the identified hazards and the analysis of their risk level, the root cause of each potential accident was investigated. When the root causes of the accidents that might result in high risks have been identified, options for controlling the risk were put forward for consideration using cost-benefit analysis. The purposes of risk control are: to focus on risk area needing control, to identify potential risk control measures, to evaluate the effectiveness of the risk control measures, and to group risk control measures into practical regulatory options [9].

\subsection{Cost-benefit assessment}

The purposes of cost-benefit assessment are to identify the costs and benefits associated with risk control options suggested in the previous step. These consist of: considering the root causes of each risk identified in risk analysis, rank the risk control options based on 
their costs and benefit of implementation, estimate the cost-effectiveness of each risk control option compare to the potential risk reduction obtained, make a decision based on the costs and benefits ranks and the cost-effectiveness of the options.

\subsection{Recommendations for decision making}

Upon concluding the cost and benefit assessment recommendations should be forwarded to the relevant decision-makers to be considered for improving the safety strategy and regulations so that the root causes of the risks identified could be solved and the accidents could be minimized. In relation the object of the study the decision maker about the port facilities and human resources is the Port Authority of Port of Tanjung Priok, and with regard to the ships and their management are the ship owners or ship operators.

\section{Results of the assessment}

Following the five steps of Formal Safety Assessment introduced by the International Maritime Organization, the results of the assessment are:

Hazards related to the potential accidents that may occur in the port of Tanjung Priok navigation area are collision, grounding, fire and explosion, sink, contact damage, engine failure, and others. For focussing of the study, only two most dominant hazards were investigated for the assessment, i.e. collision and grounding. Based on the available accident reports and discussion with authorized people in the port of Tanjung Priok it was concluded that the potential causes of these hazards are (i) for collision: navigation problems, human factors, mooring or anchoring failures; (ii) for grounding: environment conditions, navigation error, and equipment damage.

In order to determine the risk level of the accidents occurred at the port of Tanjung Priok a risk matrix as shown in Table 4 was created based on the data obtained from Figure 1 and Figure 2, where the most frequent accidents occurred are collision and grounding which in the category of frequent, and for the severity during the recorded $5 \mathrm{yr}$ period there was no human death or fatal injury nor total damage of ship or structure, only human injuries and damage to ships, which in the category of moderate. The highest hazard for collision is navigation error, and for grounding is the effect of weather, and the risk level for these two types of accidents was 15, which means tolerable. Then based on the results of risk analysis, the two highest risk accidents were investigated for their root causes using Fault Tree Analysis method [10].

Table 4. Risk matrix

\begin{tabular}{clll}
\hline \multirow{2}{*}{ Probability } & \multicolumn{3}{c}{ Consequence / Severity } \\
\cline { 2 - 4 } Frequent (5) & Major (5) & Moderate (3) & Minor (1) \\
Likely (4) & Intolerable & Tolerable & Acceptable \\
Occasionally (3) & Tolerable & Tolerable & Acceptable \\
Seldom (2) & Tolerable & Tolerable & Acceptable \\
Unlikely (1) & Acceptable & Acceptable & Acceptable \\
\hline
\end{tabular}

Fault tree analysis to investigate the root causes of navigation error which the main hazard for ships collision is presented in Figure 3, and fault tree analysis to investigate the root causes of weather effect which the main hazard for ships grounding is presented in Figure 4. 


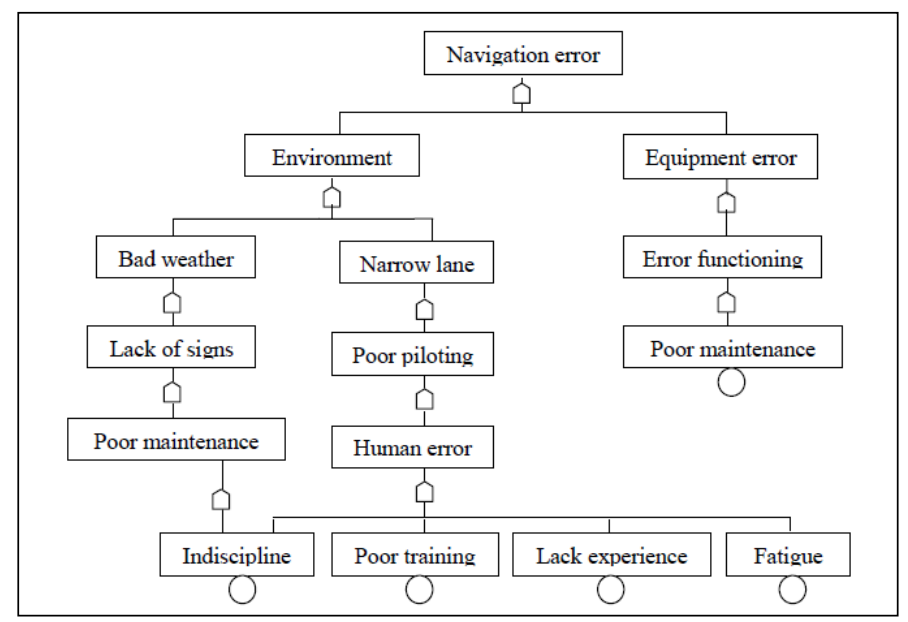

Fig. 3 FTA of navigation error

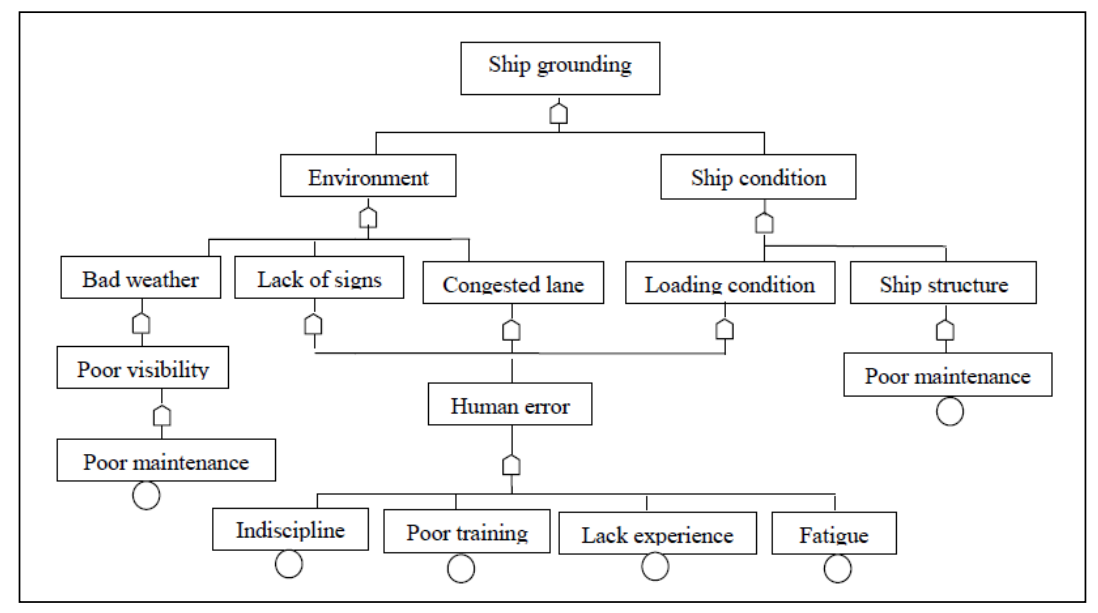

Fig. 4 FTA of ship grounding

Risk control options for preventing collision and grounding are: (i) Action for management (Recruiting qualified work force, Improve corporate safety management, implementing International Safety Management codes, review corporate regulations, and pay attention to the crews welfare). (ii) Action for port authority (strict enforcement of laws and regulations, provide appropriate navigation system, implement routine facilities maintenance system, and deploy qualified piloting crews). (iii) Action for ship crews (conduct regular safety drillings, attend appropriate training regularly, comply with the rules and regulations, implementing International Safety Management codes). (iv) Action for the ship (provide appropriate safety appliances, install navigation equipment, conduct appropriate maintenance system, comply to statutory and classification rules and regulations).

Based on the risk control options results of the cost-benefit assessment are Action for management and Action for the port authority. Since the management is beyond the reach of the study, therefore it is left to the policy of each management of the stakeholders involved in assuring the navigation safety of the port of Tanjung Priok, especially for the 
ship entering and leaving the port and their crews. Port Authority should have qualified and competent human resources to maintain appropriate implementation of rules and regulations. Provide appropriate navigation system to ensure good navigation operation. Implement routine facilities maintenance system to ensure their reliability.

Recommendation for decision making in order to increase the performance of the port of Tanjung Priok among other things are: (i) Port authority should have qualified and competent human resources to maintain appropriate implementation of rules and regulations. (ii) Appropriate Vessel Traffic Monitoring System should be used to ensure good navigation operation at the area around the port of Tanjung Priok. (iii) Reliability and Availability Maintenance System should be implemented for the port navigation facilities.

\section{Conclusions}

There are two dominant accidents identified that occurred in the port of Tanjung Priok are, i.e. collision and grounding. Hazards related to these accidents are navigation problems, human factors, mooring or anchoring failures for collision, and environmental conditions, navigation error, and equipment damage for grounding. It is recommended that Port of Tanjung Priok should have qualified and competent human resources, implement appropriate Vessel Traffic Monitoring System and implement Reliability and Availability Maintenance System.

Special appreciations are addressed to PITTA final project research grant program initiated by Directorate of Research and Community Engagement Universitas Indonesia (DRPM UI) No.2540/UN2.R3.1/HKP.05.00/2018 for funding the study and its dissemination.

\section{References}

1. N.A. Wildan, B. Untung. Jurnal Teknik Perkapalan, 3,4:1-9(2015). [in Bahasa Indonesia] https://ejournal3.undip.ac.id/index.php/naval/article/view/10530

2. IMO. Interim guidelines for the application of formal safety assessment (FSA) to the IMO rule-making processes. [MSC-MEPC.2/Circ.12/Rev.2]. London: IMO (2018). p. 8-14. $\quad$ http://www.imo.org/en/OurWork/Safety/SafetyTopics/Documents/MSCMEPC\%202-Circ\%2012-Rev\%202.pdf

3. PT. Pelindo II. Annual Report 2016 [Online] from www.priokport.co.id . [Accessed on March 30th 2018].

4. C. Kuo. Safety management and its maritime application. London: The Nautical Institute (2007). p. 48. http://www.worldcat.org/title/safety-management-and-itsmaritime-application/oclc/173843363

5. EMS. Risk acceptance criteria and risk based damage stability, report part 1: Risk acceptance criteria. Norway: DNV GL AS Maritime Advisory (2015). [Report No.: 2015-0165, Rev. 1]. [Document No.: 18KJ9LI-47]. www.emsa.europa.eu/damagestability-study/download/3547/2419/23.htm

6. A.M. Yasa, H. Ayylidiz. Formal safety assessment of offshore support vessels. Istanbul Technical University, Istanbul, Turky (2017). p. 34-49

http://gidbdergi.itu.edu.tr/sayilar/08/0803.pdf

7. M Student Life, Risk Assessment Matrix, University of Michigan, https://campusinvolvement.umich.edu/content/table-risk-assessment-matrix [Accessed on March 31st 2018].

8. D. Ristic. Safety Engineering 3,3:121-127(2013). https://www.znrfak.ni.ac.rs/SEJournal/Archive/SE-WEB\%20Journal\%20-\%20Vol3-3/pdf/3.pdf

9. Ö.F. Görçüna, S.Z. Burak. Procedia-Social and Behavioral Sciences, 207:252261(2015). https://www.sciencedirect.com/science/article/pii/S1877042815052271 
10. J. Halme, A. Aikala. J. Phys.: Conf. Ser. 364:012102(2012).

https://iopscience.iop.org/article/10.1088/1742-6596/364/1/012102/ 